\title{
Comportamento reológico de sistemas pécticos de polpas de frutas vermelhas
}

\author{
Rheological behavior of pectic systems of red fruit pulps \\ Charles Windson Isidoro HAMINIUK ${ }^{1 *}$, Maria-Rita SIERAKOWSKI ${ }^{2}$, Dayane Rosalyn IZIDORO $^{3}$,
Giselle Maria MACIEL ${ }^{4}$, Agnes de Paula SCHEER ${ }^{3}$, Maria Lucia MASSON ${ }^{3}$
}

\section{Resumo}

Neste trabalho, o comportamento reológico de sistemas pécticos formulados com as pectinas extraídas das polpas de morango, amora-preta e framboesa foi investigado através de testes reológicos oscilatórios. Adicionalmente, as propriedades químicas dessas pectinas foram estudadas. Os sistemas pécticos das polpas de frutas vermelhas apresentaram um caráter de gel forte de acordo com os testes reológicos, sendo o gel de morango caracterizado como o mais forte. Os testes reológicos foram confirmados pelo experimento de Cox-Merz, grau de esterificação e peso molecular médio. O ácido galacturônico está diretamente relacionado com a formação da rede de pectina. Além disso, a diferença entre a força dos três géis pécticos pode ser atribuída aos valores do grau de esterificação e peso molecular médio desses biopolímeros. As pectinas extraídas das frutas vermelhas estudadas neste trabalho podem ser classificadas como pectinas de alta metoxilação, apresentado o grau de esterificação maior que $50 \%$. Os três géis pécticos apresentaram uma boa estabilidade ao aumento da temperatura e ao tempo de cisalhamento oscilatório constante.

Palavras-chave: polpa de frutas vermelhas; pectina; reologia.

\begin{abstract}
In this work, the rheological behavior of pectic systems formulated with pectins extracted from strawberry, blackberry, and raspberry pulps was investigated by means of oscillatory rheological tests. In addition, the chemical properties of these pectins were studied. The pectic systems from those red fruit pulps showed a strong gel character according to the rheological tests showing that the strawberry pectin presented the strongest gel character, which was confirmed by the Cox-Merz experiment, degree of esterification, and average molecular weight data. The galacturonic acid is directly related to the formation of the pectin network. Besides, the difference between the strength of the three pectic gels can be attributed to the esterification degree values and the average molecular weight of these biopolymers. The pectins extracted from the red fruits studied in this work can be classified as high methoxy pectins with a degree of esterification higher than $50 \%$. The pectic gels exhibit good stability with an increase in temperature and in the shear-oscillatory constant time.
\end{abstract}

Keywords: red fruit pulps; pectin, reology.

\section{Introdução}

Morango, amora-preta e framboesa pertencem à família Rosaceae. De acordo com Brown (2002), a família Rosaceae é ampla e diversa, incluindo em torno de 75 gêneros e mais de 1200 espécies. Os membros desta família são valiosos por seus frutos e produtos derivados. As frutas vermelhas, como são geralmente conhecidas, têm sido usadas frequentemente pela indústria de alimentos. Os produtos manufaturados, tais como sucos, néctares, sorvetes e geléias utilizam a polpa de fruta como matéria-prima. O comportamento reológico e as propriedades de fluxo de polpas de frutas desempenham um importante papel no desenvolvimento e avaliação de equipamentos de processos tais como bombas, tubulações, trocadores de calor, evaporadores, esterilizadores e agitadores (AHMED; RAMASWAMY; NGADI, 2005). As pectinas influenciam o comportamento reológico das polpas de frutas devido as suas propriedades geilificantes. É um polissacarídeo natural, frequentemente usado como aditivo alimentar, sendo constituído, em grande parte, por unidades de ácido- $\alpha$-(1-4)-D-Galacturônico com alguns grupos carboxílicos presentes na forma metil éster (SAULNIER; BRILLOUET; JOSELEAU, 1998). A maioria dos trabalhos com morango, amora-preta e framboesa apresenta, principalmente, estudos sobre os compostos fenólicos destas frutas, bem como sua capacidade antioxidante. Os objetivos desta pesquisa foram: a) estudar a reologia em regime oscilatório das pectinas extraídas das polpas de frutas vermelhas e sua estabilidade em relação à temperatura e tempo de cisalhamento constante; b) caracterizar as pectinas de acordo com seu grau de esterificação, peso molecular médio e conteúdo de ácido galacturônico.

\footnotetext{
Recebido para publicação em 11/9/2007

Aceito para publicação em 14/1/2008 (002847)

1 Coordenação de Alimentos, Universidade Tecnológica Federal do Paraná - UTFPR, Rodovia BR, 369 Km 0,5, Campo Mourão - PR, E-mail: haminiuk@utfpr.edu.br

2 Laboratório de Biopolímeros, Universidade Federal do Paraná - UFPR, CP 19081, Curitiba - PR, E-mail: mariarita.sierakowski@ufpr.br

${ }^{3}$ Programa de Pós-Graduação em Tecnologia de Alimentos, Universidade Federal do Paraná - UFPR, CP 19011, Curitiba - PR, E-mails: dayizidoro@ufpr.br; agnesps@ufpr.br; masson@ufpr.br

${ }^{4}$ Programa de Pós-Graduação em Processos Biotecnológicos, Universidade Federal do Paraná - UFPR, CP 19011, Curitiba - PR, E-mail: gisellemariam@yahoo.com.br

${ }^{*}$ A quem a correspondência deve ser enviada
} 


\section{Material e métodos}

\subsection{Polpas de frutas vermelhas}

As polpas de morango (Fragaria vesca), amora-preta (Rubus spp.) e framboesa (Rubus idaeus) foram compradas da marca Mais Fruta. O objetivo de se utilizar as polpas comerciais foi obter uma matéria-prima padronizada e diminuir possíveis interferentes relacionados ao tamanho das partículas das polpas produzidas em escala-piloto.

\section{Análises físico-químicas das polpas de frutas vermelhas}

Os sólidos solúveis totais ( $\left.{ }^{\circ} \mathrm{Brix}\right)$ e $\mathrm{pH}$ foram determinados usando-se um refratômetro (WY1A; ABBE, USA) e pHmetro (model 710 A; Orion Research, Boston, USA) a $20^{\circ} \mathrm{C}$, respectivamente. A acidez titulável e a umidade das polpas foram medidas de acordo com a metodologia descrita na AOAC (2000).

\subsection{Extração das pectinas}

Uma amostra de cada polpa de fruta vermelha (100 g) estudada neste trabalho foi colocada em refluxo em etanol quente $\left(95^{\circ} \mathrm{C}\right)$ por 30 minutos. Subsequentemente, a amostra foi resfriada à temperatura ambiente $\left(25^{\circ} \mathrm{C}\right)$, lavada com etanol $80 \%$ $(\mathrm{v} / \mathrm{v})$ e filtrada com filtro Whatman $\mathrm{n}^{\circ} 1$. O resíduo insolúvel em álcool, denominado (RIA) foi seco em estufa à temperatura de $40{ }^{\circ} \mathrm{C}$ por 24 horas, pesado e armazenado em dessecador.

\section{Conteúdo de ácido galacturônico das pectinas extraídas}

O conteúdo de ácido galacturônico das pectinas extraídas das três polpas de frutas foi determinado através do uso de Espectrofotômetro na faixa de onda de $520 \mathrm{~nm}$ pelo método alcalino do m-hidroxibifenil, de acordo com a metodologia clássica de Blumenkrantz e Asboe-Hansen (1973), utilizando o ácido D-Galacturônico mono-hidratado (Voigt Global, Kansas City, USA) como padrão.

\section{Grau de esterificação das pectinas}

A determinação do grau de esterificação (DE) das amostras de pectinas foi conduzida de acordo com a metodologia proposta por Monsoor et al. (2001). Foi utilizado um Espectrofotômetro Bomen Infravermelho Transformada de Fourier (FT-IR), (Bomen Inc., Canadá), com um disco de $\mathrm{KBr}$. Os espectros FT-IR foram obtidos por coadicionar 32 varreduras ("scans") utilizando uma resolução de $4.0 \mathrm{~cm}^{-1}$. Os espectros foram coletados usando um disco branco, o qual foi subtraído do espectro de cada amostra de pectina para compensar a absorção do $\mathrm{CO}_{2}$ e umidade do ar. A Equação 1 foi usada para calcular o grau de esterificação (GE) das amostras de pectinas:

$$
G E=\left[\frac{A P G C E}{(A P G E+A P G C N E)}\right] \times 100
$$

onde, APGCE é a área dos picos dos grupos carboxílicos esterificados e APGCNE é a área dos picos dos grupos carboxílicos não-esterificados. Picos na faixa de $1760-1745 \mathrm{~cm}^{-1}$ indicam os grupos éster-carboxílicos (COO-R) e aqueles na faixa de
1640-1620 indicam os grupos não-éster-carboxílicos (COO-). Três replicatas da análise de FTIR foram realizadas.

\section{Determinação do peso molecular médio $\left(M_{w}\right)$}

O peso molecular médio das pectinas extraídas das polpas de frutas vermelhas foi estimada aplicando a Equação 2 de Mark Houwink-Sakurada, relacionando [ $\eta$ ] com $\mathrm{M}_{\mathrm{w}}$ (ARSLAN, 1995).

$[\eta]=k\left[M_{w}\right]^{a}$

onde, $\mathrm{K}$ e a são constantes e [ $\eta$ ] é a viscosidade intrínseca definida de acordo com a Equação 3:

$[\eta]=\operatorname{Lim}_{C \rightarrow 0}\left(\frac{\eta_{r}-1}{C}\right)$

onde, $\eta_{\mathrm{r}}$ é a viscosidade relativa (solução para solvente) e C é a concentração de pectina. Ambas as constantes $\mathrm{K}$ e a dependem da temperatura e das características do solvente e do soluto. No caso de solução de pectina em tampão fosfato de sódio $\left(0,1\right.$ mol. L $\mathrm{L}^{-1}$; $\left.\mathrm{pH} 7,0\right)$, pode-se assumir o valor de $\mathrm{K}$ como $0,3 \mathrm{e}$ o de a como 0,613 (ARSLAN, 1995). A determinação foi feita na faixa de concentração de pectina de 1,0 a 9,0 g. $\mathrm{L}^{-1}$ em triplicata. A medição das viscosidades foi realizada a $25^{\circ} \mathrm{C}$, utilizando um reômetro Haake Reostress 600 (Haake, Karlsruhe, Alemanha), utilizando um sistema cone-placa (C-60/2。 $\mathrm{Ti})$.

\section{Preparação dos sistemas pécticos}

A pectina extraída de cada polpa foi incorporada em água destilada sob agitação magnética a $25^{\circ} \mathrm{C}$ por 24 horas em uma concentração de $5 \%$ (p/v) com o objetivo de obter os sistemas pécticos.

\section{Análises reológicas dos sistemas pécticos}

As análises reológicas em regime oscilatório foram realizadas em reômetro Haake Rheostress 600 (Haake, Karlsruhe, Alemanha), acoplado a um sensor cone-placa (C-60/2 $\mathrm{Ti}$, com abertura de $100 \mu \mathrm{m}$ ) a $20^{\circ} \mathrm{C}$. Segundo Scharamm (2000), quanto menor o tamanho da abertura entre o cone e a placa, mais confiáveis serão os valores obtidos. Antes de realizar as análises dos espectros mecânicos (módulos G’e G” em função da frequência) foi realizada uma varredura de tensão na faixa de 0 a $100 \mathrm{~Pa}$ em diferentes valores de frequência $(0,05 \mathrm{~Hz}, 0,1 \mathrm{~Hz}$ e $1 \mathrm{~Hz})$ com o objetivo de determinar a região viscoelástica de cada sistema péctico. Neste estudo, após a varredura de tensão, os valores de tensão determinados para a varredura de frequência foram $10 \mathrm{~Pa}$, para o sistema péctico de morango (SPM), e $1 \mathrm{~Pa}$, para os sistemas pécticos de amora-preta (SPA) e framboesa (SPF). A varredura de frequência nas amostras dos sistemas pécticos foi feita em deformação oscilatória de baixa amplitude, na faixa de 0,01 a $10 \mathrm{~Hz}$ na temperatura de $20^{\circ} \mathrm{C}$. Os testes de reologia oscilatória foram realizados em duplicata.

Análises reológicas dos sistemas pécticos - regime oscilatório (varredura de temperatura e tempo)

Com o objetivo de melhor caracterizar os sistemas pécticos, foi avaliada a estabilidade destes em função da temperatura e 
do tempo. Para a varredura de temperatura, utilizou-se uma frequência de $1 \mathrm{~Hz}$ e uma deformação de $5 \%$, com a temperatura variando de 20 a $60{ }^{\circ} \mathrm{C}$ com uma taxa de aquecimento de $0,017^{\circ} \mathrm{C} / \mathrm{s}$. Em relação ao estudo dos sistemas pécticos em função do tempo de deformação oscilatória, utilizou-se uma frequência de $1 \mathrm{~Hz}$ e uma deformação de $5 \%$ em um intervalo de tempo de 30 minutos (1800s).

\section{Análise estatística}

Os dados obtidos foram submetidos à análise de variância e a diferença entre as médias foi analisada através do teste de Tukey ao nível de significância de 5\%.

\section{Resultados e discussão}

\subsection{Caracterização da matéria-prima}

A Tabela 1 apresenta as análises físico-químicas realizadas nas polpas integrais das polpas de frutas vermelhas. Para as pectinas extraídas, determinou-se o grau de esterificação, peso molecular médio, viscosidade intrínseca e conteúdo de ácido galacturônico, sendo que estes valores podem ser encontrados na Tabela 2. Relacionado às características físico-químicas, pode-se observar que não houve diferença estatística para os valores de $\mathrm{pH}$ e umidade das três polpas de frutas vermelhas. No entanto, em relação aos sólidos solúveis e acidez titulável, houve diferença significativa $(\mathrm{p} \leq 0,05)$.

Através da análise da Tabela 2, fica evidente a diferença entre os valores obtidos para os quatro parâmetros determinados para as três polpas estudadas. Em relação ao conteúdo de ácido galacturônico, o qual corresponde a $70 \%$ da estrutura primária das pectinas, houve diferença significativa entre os valores obtidos, sendo que a pectina extraída da polpa de morango apresentou a maior quantidade de ácido galacturônico em comparação com as outras pectinas extraídas. Este comportamento se repete em

Tabela 1. Caracterização físico-química das polpas integrais de frutas vermelhas.

\begin{tabular}{lrcr}
\hline \multicolumn{1}{c}{ Parâmetros } & $\begin{array}{r}\text { Polpa de } \\
\text { morango }\end{array}$ & $\begin{array}{c}\text { Polpa de } \\
\text { amora-preta }\end{array}$ & $\begin{array}{c}\text { Polpa de } \\
\text { framboesa }\end{array}$ \\
\hline Polpas integrais & & & \\
Sólidos solúveis ( ${ }^{\circ}$ Brix) & $6,10^{\mathrm{a}}$ & $5,75^{\mathrm{a}}$ & $6,95^{\mathrm{b}}$ \\
pH & $3,60^{\mathrm{a}}$ & $3,60^{\mathrm{a}}$ & $3,30^{\mathrm{a}}$ \\
Acidez titulável (g.100 $\left.\mathrm{mL}^{-1}\right)$ & $0,69^{\mathrm{a}}$ & $0,57^{\mathrm{a}}$ & $1,09^{\mathrm{b}}$ \\
Umidade (\%) & $92,48^{\mathrm{a}}$ & $93,15^{\mathrm{a}}$ & $92,10^{\mathrm{a}}$ \\
\hline * Médias com letras iguais não são estatisticamente
\end{tabular}

* Médias com letras iguais não são estatisticamente diferentes $(\mathrm{p} \leq 0,05)$.

Tabela 2. Caracterização química e física das pectinas extraídas das polpas de morango, amora-preta e framboesa.

\begin{tabular}{lccc}
\hline \multicolumn{1}{c}{ Parâmetros } & $\begin{array}{c}\text { Pectina de } \\
\text { morango }\end{array}$ & $\begin{array}{c}\text { Pectina de } \\
\text { amora-preta }\end{array}$ & $\begin{array}{c}\text { Pectina de } \\
\text { framboesa }\end{array}$ \\
\hline Ácido galacturônico $\left(\mu \mathrm{g} \cdot \mathrm{mL}^{-1}\right)$ & $56,50^{\mathrm{a}}$ & $27,87^{\mathrm{c}}$ & $43,77^{\mathrm{b}}$ \\
Peso molecular médio $\left(\mathrm{g} \cdot \mathrm{mol}^{-1}\right)$ & $101.434^{\mathrm{a}}$ & $62.865^{\mathrm{c}}$ & $78.332^{\mathrm{b}}$ \\
Viscosidade intrínseca $\left(\mathrm{mL} \cdot \mathrm{g}^{-1}\right)$ & $351,49^{\mathrm{c}}$ & $262,15^{\mathrm{c}}$ & $299,99^{\mathrm{b}}$ \\
Grau de esterificação (\%) & $67,28^{\mathrm{a}}$ & $56,61^{\mathrm{c}}$ & $61,82^{\mathrm{b}}$ \\
\hline${ }^{*}$ Médias com letras iguais não são estatisticamente diferentes $(\mathrm{p} \leq 0,05)$.
\end{tabular}

* Médias com letras iguais não são estatisticamente diferentes $(\mathrm{p} \leq 0,05)$. relação aos dados obtidos para o peso molecular médio, viscosidade intrínseca e grau de esterificação, apresentando a pectina de morango os maiores valores. A três pectinas extraídas podem ser consideradas como pectinas com alto grau de metoxilação, por apresentarem mais de $50 \%$ das carbonilas esterificadas com grupos metil $\left(-\mathrm{COOCH}_{3}\right)$.

\subsection{Comportamento reológico}

Para a determinação do comportamento dos sistemas pécticos, foi realizada uma varredura de tensão em cada sistema obtido, com o objetivo de se determinar a região viscoelástica. A região viscoelástica é conhecida por ser a região onde a estrutura do gel é preservada, ou seja, os módulos de armazenamento (G’) e de perda (G”) são independentes da frequência. É de fundamental importância a análise em regime oscilatório ser realizada nesta região, pois, de forma diferente, os valores dos módulos serão muito menores devido ao cisalhamento e à destruição da rede péctica. As Figuras 1 a 3 apresentam a relação entre os módulos (G' e G') e a tensão nas três frequências estudadas para os sistemas pécticos.

Pela interpretação das Figuras de 1 a 3, determinou-se a região viscoelástica para os três sistemas pécticos em função da tensão. Para o sistema péctico de morango (SPM), a tensão escolhida foi $10 \mathrm{~Pa}$, pois acima deste valor os módulos elástico e viscoso começaram a apresentar dependência da tensão. Para os sistemas pécticos de amora-preta (SPA) e de framboesa (SPF), a tensão escolhida foi $1 \mathrm{~Pa}$.

De acordo com os dados obtidos na região viscoelástica, a deformação do Sistema Péctico de Morango (SPM) sob uma tensão de $10 \mathrm{~Pa}$ foi menor do que $3 \%$, enquanto que para

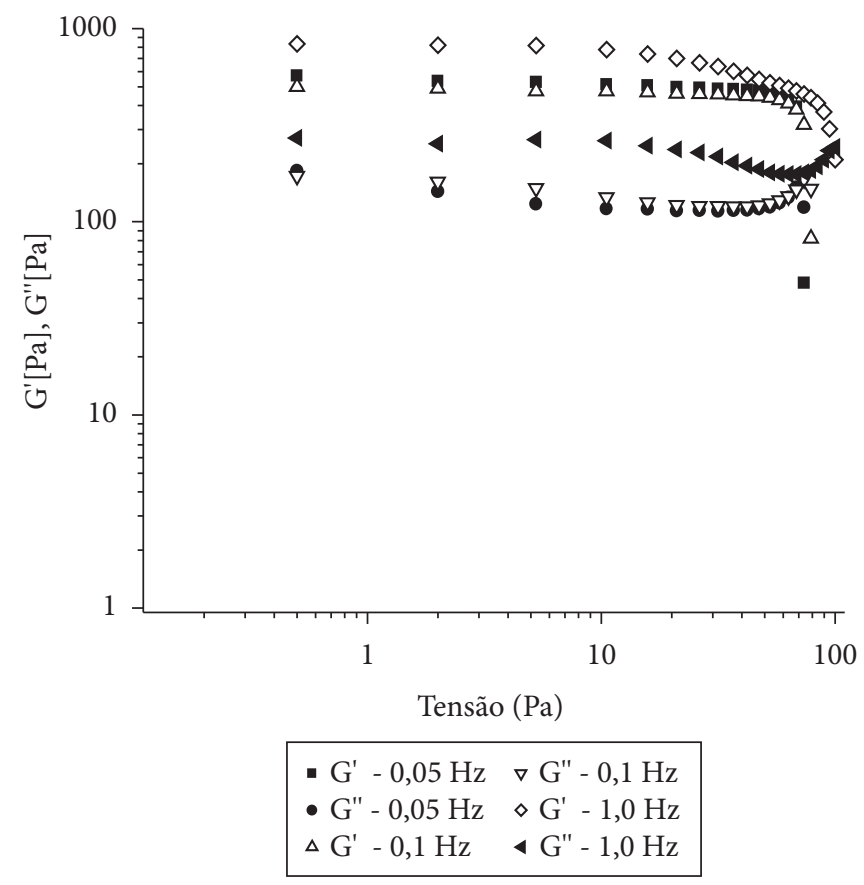

Figura 1. Região viscoelástica para o sistema péctico de morango (10 Pa) na temperatura de $20^{\circ} \mathrm{C}$, sensor de medida C-60/2 $\mathrm{Ti}$, com abertura de $100 \mu \mathrm{m}$. 
o Sistema Péctico de Amora-Preta (SPA) e Sistema Péctico de Framboesa (SPF) sob uma tensão de $1 \mathrm{~Pa}$, as deformações foram 0,46 e 0,38\%, respectivamente. Para a caracterização da força dos sistemas pécticos das três polpas de frutas vermelhas, foi realizada uma varredura de frequência (baixa amplitude) na faixa de 0,01 a $10 \mathrm{~Hz}$, aplicando os valores das tensões obtidos

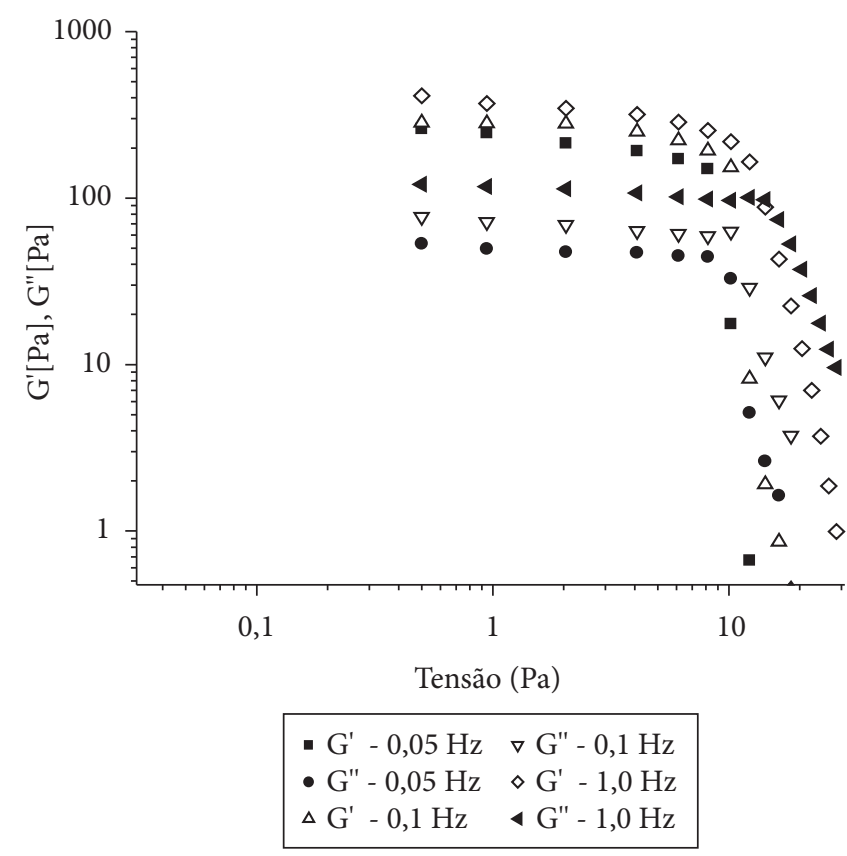

Figura 2. Região viscoelástica para o sistema péctico de amora-preta (1 Pa) na temperatura de $20^{\circ} \mathrm{C}(1 \mathrm{~Pa})$, sistema de medida C-60/2 ${ }^{\circ} \mathrm{Ti}$, com abertura de $100 \mu \mathrm{m}$.

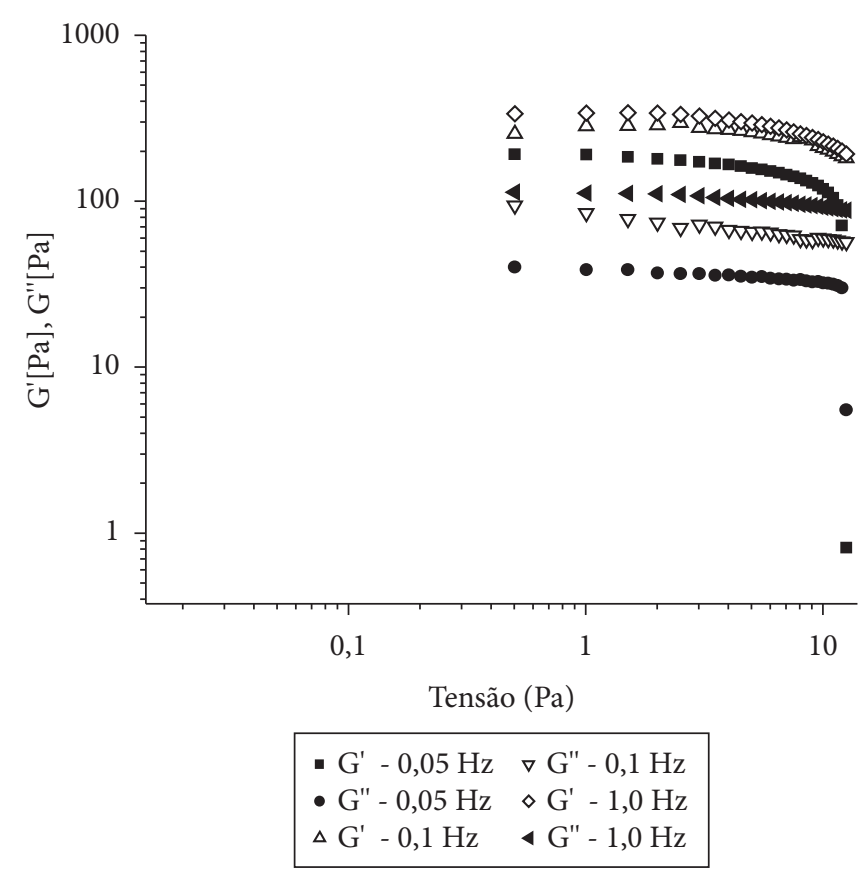

Figura 3. Região viscoelástica para o sistema péctico de framboesa (1 Pa) na temperatura de $20^{\circ} \mathrm{C}(1 \mathrm{~Pa})$, sistema de medida C-60/2 ${ }^{\circ} \mathrm{Ti}$, com abertura de $100 \mu \mathrm{m}$. na região viscoelástica pela relação entre os módulos x tensão. A Figura 4 mostra a variação de G' e G” (espectro mecânico) como uma função da frequência na temperatura de $20^{\circ} \mathrm{C}$. Através deste gráfico, pode-se observar que os três sistemas pécticos estudados formam géis fortes, uma vez que G'(módulo de armazenamento) foi maior que G" (módulo elástico) em toda a faixa de frequência. Com o aumento da frequência não foi observado o "fenômeno de crossover", ou seja, a interseção entre os dois módulos.

Uma vez determinado que os sistemas pécticos possuem caráter de gel, a partir deste ponto passou-se a considerá-los como géis e não mais como um sistema. Neste trabalho, os valores da tangente $(\delta)$, que é a razão entre G'/G” (NAÉ, 1993), foram utilizados para caracterizar a força dos géis pécticos. Os valores da tangente $(\delta)$ foram considerados inversamente proporcionais à força dos géis. Comparando os três tipos de géis pécticos obtidos, o GPM (Gel Péctico de Morango) demonstrou ser mais forte quando comparado com GPA (Gel Péctico de Amora-Preta) e GPF (Gel Péctico de Framboesa). Por outro lado, GPF mostrou ser um gel mais forte que GPA. Esses resultados podem ser associados com a quantidade de ácido galacturônico encontrada durante as análises químicas e físicas das pectinas (Tabela 2). O ácido galacturônico está diretamente relacionado com a formação da rede de pectina. Além disso, a diferença entre a força dos três géis pécticos pode ser atribuída aos valores do grau de esterificação e peso molecular médio desses biopolímeros. As pectinas extraídas dessas frutas vermelhas estudadas neste trabalho podem ser classificadas como pectinas de alta metoxilação, apresentando o grau de esterificação maior que $50 \%$. A pectina de morango apresentou os maiores valores de grau de esterificação e peso molecular médio $(67,28 \%$ e

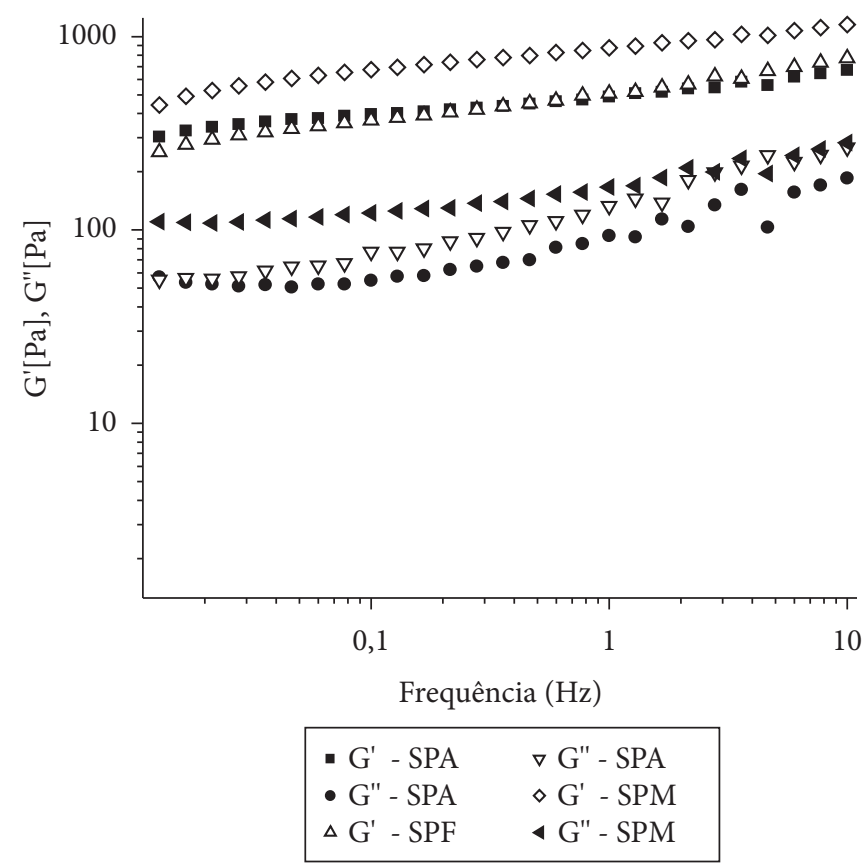

Figura 4. Varredura de frequência a $20{ }^{\circ} \mathrm{C}$ dos sistemas pécti$\cos (5 \% \mathrm{~m} / \mathrm{v})$. G' (módulo de armazenamento) e G” (módulo de perda). SPM - Sistema Péctico de Morango; SPA - Sistema Péctico de Amora-Preta; SPF - Sistema Péctico de Framboesa. Sensor de medida C-60/2 $2^{\circ} \mathrm{Ti}$, com abertura de $100 \mu \mathrm{m}$. 
101.434 g. mol $^{-1}$, respectivamente) e esses dados explicam porque o gel obtido com essa pectina foi mais forte do que aqueles obtidos com as pectinas de amora-preta e framboesa.

Para melhor caracterizar as propriedades reológicas dos géis pécticos de morango (GPM), amora-preta (GPA) e framboesa (GPF), realizou-se o experimento de Cox-Merz. A relação de Cox-Merz está apresentada na Equação 4:

$\eta^{*}(\omega)=\eta_{a p}(\gamma) \omega=\gamma$

onde, $\eta^{\star}$ é a viscosidade dinâmica complexa (mPa.s), $\eta_{\mathrm{ap}}$ é a viscosidade aparente de cisalhamento ( $\mathrm{mPa} . \mathrm{s}), \omega$ é a frequência de oscilação $(\mathrm{rad} / \mathrm{s})$ e $\gamma$ é a taxa de cisalhamento $\left(\mathrm{s}^{-1}\right)$. Se a viscosidade dinâmica complexa plotada em relação à frequência for consistentemente maior do que a viscosidade aparente plotada em relação à taxa de cisalhamento, pode-se afirmar que existe uma estrutura de gel (HAN et al. 2002, ROBERTS; CAMERON, 2002).

Através do gráfico de Cox-Merz (Figura 5), pode-se observar que, nas três amostras de géis pécticos, a viscosidade dinâmica complexa foi muito maior que a viscosidade aparente de cisalhamento, confirmando a natureza forte dos géis obtidos. É interessante observar que a dependência da viscosidade dinâmica complexa em relação à frequência comportou-se diferentemente quando comparada com a viscosidade aparente em similares faixas de frequência/taxa de cisalhamento para os três géis pécticos estudados. Esta diferença é provavelmente o resultado da interação entre partículas e a cadeia estrutural complexa dos géis pécticos, a qual não ocorre em medidas, utilizando pequenas oscilações. Em regime permanente de fluxo, a deformação é maior e a cadeia estrutural rompe em altas taxas de cisalhamento (AHMED, 2004).

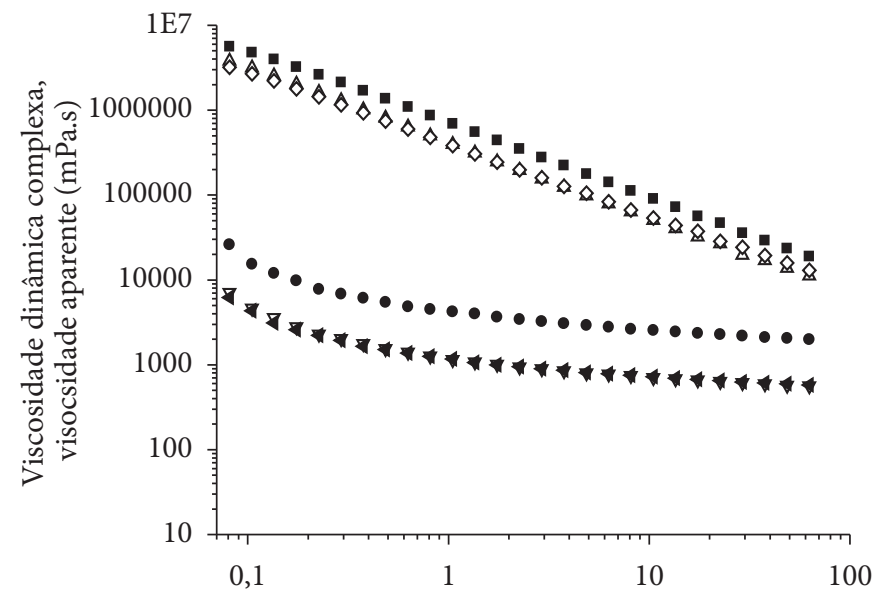

Frequência ( $\mathrm{rad} / \mathrm{s})$, taxa de cisalhamento $\left(\mathrm{s}^{-1}\right)$

$$
\begin{array}{ll}
\text { - } \eta^{*}-\mathrm{GPM} & \nabla \eta_{\text {ap }}-\mathrm{GPF} \\
\text { - } \eta_{\mathrm{ap}}-\mathrm{GPM} & \diamond \eta^{*}-\mathrm{GPA} \\
\Delta \eta^{*}-\mathrm{GPF} & \triangleleft \eta_{\mathrm{ap}}-\mathrm{GPA}
\end{array}
$$

Figura 5. Gráfico de Cox-Merz para os géis pécticos a $20^{\circ} \mathrm{C}(5 \% \mathrm{~m} / \mathrm{v})$. $\eta^{*}$ - Viscosidade Dinâmica Complexa; $\eta_{\text {ap }}$ - Viscosidade Aparente de Cisalhamento. GPM (Gel Péctico de Morango); GPF (Gel Péctico de Framboesa) e GPA (Gel Péctico de Amora-Preta).
Adicionalmente, a dependência de G' das três amostras de géis pécticos em função da frequência angular foi modelada por uma relação, utilizando um modelo de potência (Equação 5).

$\mathrm{G}=\mathrm{A} \omega^{\mathrm{b}}$

onde, A e b são constantes empíricas. Uma regressão linear de $\log \omega$ versus $\log G^{\prime}$ resultou no ajuste de uma linha reta. Os coeficientes de determinação obtidos foram 0,97 para GPM, 0,98 para o GPA e 0,99 para o GPF, enquanto que o erro padrão foi menor que 0,006 para os três géis pécticos. Os coeficientes angulares estimados foram de 0,10 para GPM, 0,16 para o GPA e 0,13 para o GPF. Um gel verdadeiro é caracterizado por um coeficiente angular (slope) de log de $\omega$ versus log G’ próximo de zero (ROSS-MURPHY, 1984), enquanto que um gel fraco, soluções concentradas ou dispersões terão um valor do coeficiente angular distantes positivamente de zero. Esta análise mais uma vez mostra o caráter forte dos géis pécticos obtidos.

Buscando um melhor entendimento dos géis pécticos, foi estudado o efeito da temperatura (faixa de 20 a $60{ }^{\circ} \mathrm{C}$ com incremento de $1{ }^{\circ} \mathrm{C} /$ minuto) e do tempo de cisalhamento (30 minutos). O objetivo desses dois testes foi avaliar a estabilidade dos três géis com o aumento progressivo da temperatura e com um cisalhamento oscilatório constante. O derretimento e o comportamento viscoelástico podem variar grandemente, dependendo da origem do biopolímero e das condições de geleificação (Tischer et al., 2006). Uma vez que a temperatura pode influenciar grandemente os biopolímeros, após observar a variação dos módulos em função da frequência, nós examinamos a influência da temperatura em relação ao comportamento viscoelástico dos géis pécticos.

A Figura 6 mostra o efeito da temperatura nos géis pécticos extraídos de polpas de frutas vermelhas. Conforme ilustrado na Figura 6a, com o aumento progressivo da temperatura, o gel péctico de morango (GPM) apresentou uma boa estabilidade, mantendo a característica de um gel forte $\left(G^{\prime}>G^{\prime \prime}\right)$. O gel péctico de amora-preta, da mesma forma que o GPM, manteve a sua estrutura de gel com o aumento da temperatura (Figura 6b). Observa-se que houve uma tendência de aumento do módulo G' Já o gel péctico de framboesa com o aumento progressivo de calor, apresentou um distanciamento dos módulos G’ e G”. Este comportamento pode ser atribuído à perda de água durante o aquecimento, embora se tenha coberto com uma fina camada de óleo os limites entre o sistema cone-placa e a amostra para evitar a perda de umidade. Da mesma forma que GPM e GPA, o GPF manteve as características de um gel forte com a variação da temperatura (Figura 6c).

O efeito do tempo de cisalhamento em regime oscilatório nos três géis pécticos estudados está apresentado na Figura 7. De uma forma geral, o tempo teve pouca influência nos géis pécticos. Pela análise dos módulos de armazenamento e de perda, verifica-se que num tempo de 1800 segundos, $G$ ' apresentou um distanciamento constante de G”. Esta análise confirma os resultados obtidos pela análise dos módulos em função da frequência e pelo experimento de Cox.Merz, no qual as pectinas extraídas das polpas vermelhas apresentam a capacidade de formar um gel forte. 

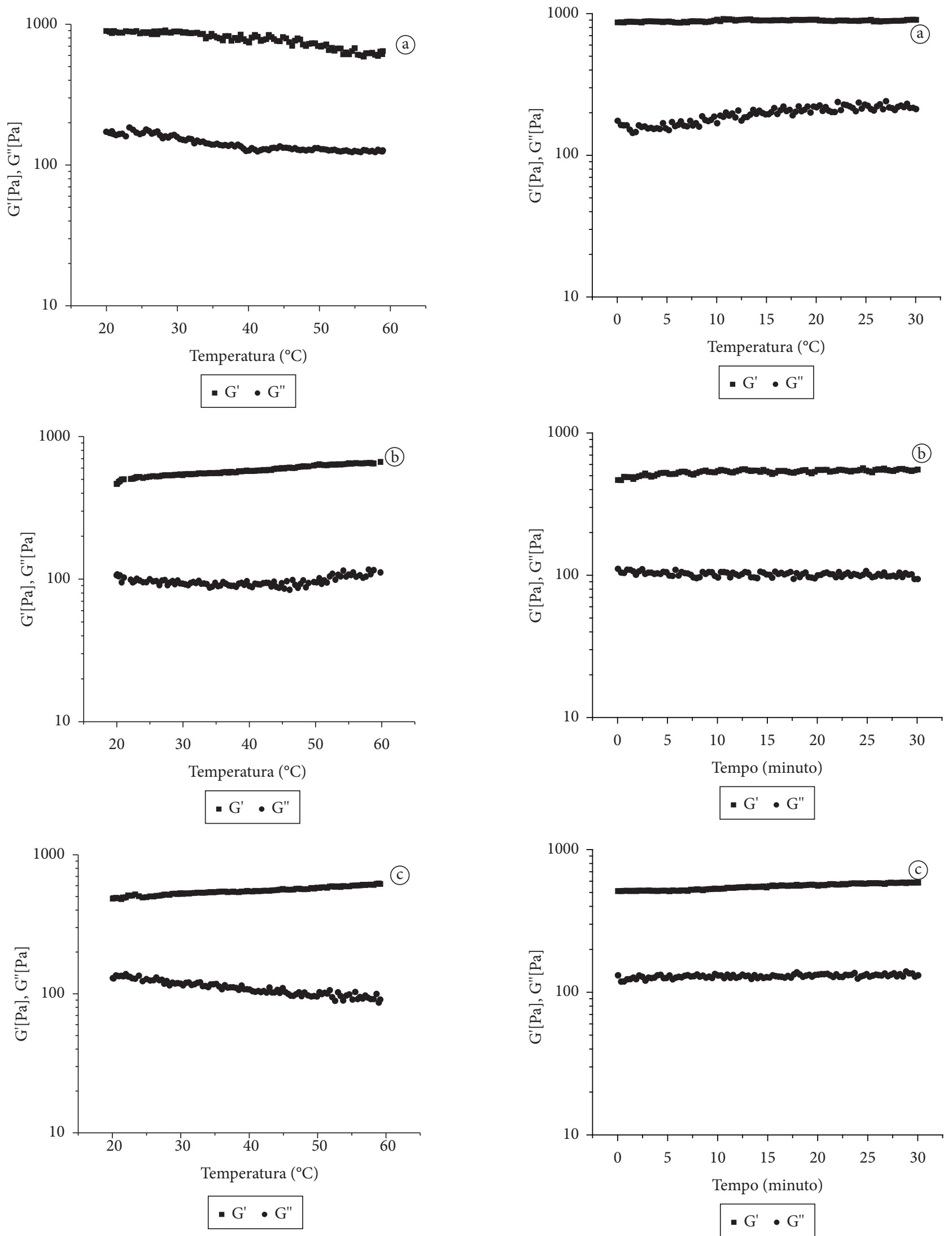

Figura 6. Efeito da temperatura nos géis pécticos $(5 \% \mathrm{~m} / \mathrm{v})$ de Morango a), Amora-preta b) e Framboesa c). Frequência de $1 \mathrm{~Hz}$ e uma deformação de $5 \%$.

Figura 7. Efeito do tempo de cisalhamento nos géis pécticos $(5 \% \mathrm{~m} / \mathrm{v})$ de Morango a), Amora-Preta b) e Framboesa c). Frequência de $1 \mathrm{~Hz}$ e uma deformação de $5 \%$. 


\section{Conclusões}

Um comportamento reológico típico de gel foi determinado para os sistemas pécticos utilizando as pectinas extraídas das polpas de frutas vermelhas, sendo isso confirmado pelos experimentos de Cox-Merz e pelos valores da tangente $(\delta)$. O gel péctico de morango (GPM) foi considerado o mais forte, em comparação com o gel géctico de amora-preta (GPA) e o gel péctico de framboesa (GPF), sendo esta afirmação confirmada pelos valores do grau de esterificação das pectinas, peso molecular médio e conteúdo de ácido galacturônico. Os três géis pécticos apresentaram uma boa estabilidade ao aumento da temperatura e ao tempo de cisalhamento oscilatório constante. Investigações futuras utilizando microscopia eletrônica de varredura (MEV) poderão esclarecer os diferentes comportamentos observados nos géis pécticos das frutas vermelhas estudadas.

\section{Referências bibliográficas}

BROWN, D. The Royal Horticultural Society. New Encyclopedia of Herbs and their Uses. London: Dorling Kindersley, 2002.

AHMED, J.; RAMASWAMY, H. S.; NGADI, O. Rheological characteristics of Arabic gum in combination with guar and xanthan gum using response surface methodology: effect of temperature and concentration. International Journal of Food Properties, v. 8, n. 2, p. 79-192, 2005.

SAULNIER, L.; BRILLOUET, J. M.; JOSELEAU, J. P. Structural studies of pectic substances from the pulp of grape berries. Carbohydrate Research, v. 182, n. 1, p. 63-78, 1998.

AOAC. Official Methods of Analysis. 17 ed. Gaithersburg, Maryland, USA, 2000.
BLUMENKRANTZ, N.; ASBOE-HANSEN, G. New method for quantitative determination of uronic acids. Analytical Biochemistry, v. 54, n. 2, p. 484-489, 1973.

MONSOOR, M. A.; KULAPATHY, U.; PROCTOR, A. Improved method for determination of pectin degree of esterification by diffuse reflectance fourier transform infrared spectroscopy. Journal of Agricultural and Food Chemistry, v. 49, n. 6, p. 2756-2760, 2001.

ARSLAN, N. Extraction of pectin from sugar-beet pulp and intrinsic viscosity-molecular weight relationship of pectin solutions. Journal of Food Science and Technology, v. 32, n. 5, p. 381-385, 1995.

SCHARAMM, G. A pratical approach to rheology and rheometry. 2 ed. Karlsruhe, Germany: [s.n.], 2000.

NAÉ, H. N. Introduction to rheology. In: Rheological Properties of Cosmetics and Toiletries. Laba, D. (Ed.). New York, NY: Marcel Dekker, 1993.

HAN, X. Z. et al. Influence of maize starch granule-associated protein on the rheological properties of starch pastes. Part II. Dynamic measurements of viscoelastic properties of starch pastes. Carbohydrate Polymers, v. 49, n. 3, p. 323-330, 2002.

ROBERTS, S. A.; CAMERON, R. E. The effects of concentration and sodium hydroxide on the rheological properties of potato starch gelatinization. Carbohydrate Polymers, v. 50, n. 2, p. 133-143, 2002.

AHMED, J. Rheological behaviour and colour changes of ginger paste during storage. International Journal of Food Science and Technology, v. 39, n. 3, p. 325-330, 2004.

ROSS-MURPHY, S. B. Rheological methods. In: Chan, H. W. S. (Ed.). Biophysical methods in food reaserch. London: Blackwell Scientific Publications, 1984.

TISCHER, P. C. S. F. T. et al. Effects of iota-carrageenan on the rheological properties of starches. Carbohydrate Polymers, v. 65, n. 1, p. 49-57, 2006. 